\title{
MEDIA CONSUMPTION AND SPACE MANAGEMENT IN THE SOCIAL SCIENCES
}

\author{
F.N. Mocănaşu
}

\section{Florentina Nina Mocănaşu}

Faculty of Journalism, Psychology and Educational Sciences, Journalism Departament, University Hyperion of Bucharest, Romania

*Correspondence:Florentina Nina Mocănaşu, Assistant Professor PhD, University Hyperion of Bucharest, Popa Nan Street, no. 90-92, Bucharest, Romania

E-mail: motornina@yahoo.com

\begin{abstract}
:
Social actors claim that sociology studies social reality as a whole, but also concerns the parts, phenomena and processes of this reality, in their many and varied relationship to the whole. In the social space there are many groups that interact in this regard, and because of this there are many types of messages to reach one or the other of the groups.Public opinion is the reaction product of people's minds and the thinking sum of individual form groupthink.

Management then applies individual problem then it analysis the public thinking. The reaction occurs using communication media between the individual and the mass of people bringing the two stakeholders to a common denominator and creating symbols that public thinking to answer.
\end{abstract}

Keywords:social actors, social space, group thinking, communication media, public opinion, management.

\section{Motto:}

Courage people can be represented as a rock, their purpose as a road, their doubts can be viewed as a crossroads of a road, difficulties as potholes and stones, progress as a fertile valley.

\section{Introduction}

Public Opinion

Contemporary management moves its sphere of interest to the extent that individual man is considered and treated in what he is for real. It must be very clear conceptually the understanding of human-centered management because it is not just a simple change practice about what is required of people but especially a fundamental change to the way the human is designed. The paradigm is the same, instead of subordinating the human to technology as was done in previous years, today we subordinate the technology to the human but on the same principal of treatment on human.

\section{The emergence and evolution of management socio-human space}

The term was originally used by management in anglo-saxon countries (England, Ireland, Scotland) but he progressed rapidly all over the globe. The word itself supports Al Graur ${ }^{1}$ originates from the latin "manus" which means hand. This term was used in italian as "mannegio" or processing by hand, then jumped in french "manege" or school riding and

\footnotetext{
${ }^{1}$ Graur Al. Arguments "for" and "against" adopting the term "management" in Romanian, Discussion Forum organized by the magazine, no. 2, 1971
} 
came in romanian with meaning "place where horses are trained." Then the british used the term "to manage" which means tomanage, to lead. The british continued to use the term with the meaning "manager" and "management".

Over the years the verb "to manage" passed in the sphere of sport horses to curb the horses into operative areas and military science. It may mistakenly believe that the time management has found resonance in the economy, it is not fulfilled either in the eighteenth century. It is used but in the political sphere and in the field of journalism. We find him and public administration with emphasis in matters of police, military and naval environment. In the last 50 years it has been used in economic activities.

So management can give many meanings of the term but all appeal to man, explicitly or implicitly, more specifically his work.

Just think of the construction of the great pyramids, the Great Wall, the great medieval castles and gothic cathedrals to accept the idea that all this would have been nearly impossible without the existence of a management built on genius measure architectonic constructor. If theantiquity and theMiddle Ages have bequeathed a series of books that describe and formulate principles and laws that formed the basis of this stunning building, we may wonder where those documents and books are to be taught the secrets and managerial methods that have enabled them to achieve success, technological conditions of those times. Abrudan (2003, p.4) I consider that such books are "the first management books are the fundamental books of humanity: the Bible, the Koran, books of asian religions, etc. I stated several times that there is a more authentic human resources management theory than Solomon's teachings. Beyond any partisan or religious affiliation, fundamental books of mankind are manual management "2

Claiming a different point of view, P. Drucker states that management was present only in businesses that produce goods or performs economic services and he underlined that "the experience of the management cannot be passed and applied to other institutions management and organization" ${ }^{3}$

After suffering numerous transformations, management initially resulted in business, but now he has broadened the scope and used in all spheres of activity; culture, medicine,sport etc. accounting activity management, administration.

Definitions of management several senses of the term:

1.Managementul is a process (activity).

2. Management is a group of people

3. Management is a science and an art.

Professor Constantin Pintilie is concerned with the sense of the concept and states that management is a means by which changes can be designed rationally human and disseminated throughout the body in the social field.Activity in management domain is considered one of the basic factors of economic growth, the same importance as advanced technique.

A sense accepted by many is that management becomes a conscious process management and coordination of actions and individual and group activities and resource mobilization and allocation organization to meet its objectives consistent with the mission, the goals and the responsibility of its economic and social.

Multiple explanations of the concept of management made it to L. Brech to believe that its meaning is not always clear or universally accepted ${ }^{4}$. Today, worldwide although management is unanimously recognized as indispensable but has become particularly controversial.

\footnotetext{
${ }^{2}$ http://www.academia.edu/5712362/C_Bratianu_-_Management_si_Marketing

${ }^{3}$ Drucker, PF, La practique from directiondesentreprises, Les Editions d Organisation, Paris, 1957, p.8

${ }^{4}$ Petrescu. I, Management, Publishing Holding Reporter, Bucharest, 1991, p.14
} 


\section{Romanian management}

In Romania only in the nineteenth century more precisely in recent years that the notion of managerial culture in two forms:

- $\quad$ Processing concepts of management classics

- $\quad$ The development of romanian works with management implications

DP Martian BPHaşdeu, ADXenopol were few specialists who have studied the many problems formation and development of Romanian national economic complex.Romanian school representatives support the idea that there can be an economic science valid for all countries, but rather is necessary for each country to base its economic science.

A supporter of Romania was and PS Aurelian. It argued in 1872 that: Romania is not anybody column to be imposed by force not to create any industry, it is an independent country and as such has the right and duty to encourage domestic industry..$^{5}$

In Romania managerial impacts led to significant practical changes. This was possible because they were designed and implemented with a strategy premise.

The characteristics of this strategy can be applied and understood only as part of a group strategy. They are grouped in Romania as follows:

1. territorial and sectorial strategies for ordering accelerated restructuring and privatization;

2. strategy of developing the attractiveness of economic or social domains and subdomains;

After the Second World War following a long interruption and stagnation in the concerns and actions of the management of theory and practice plan in Romania. There have been abolished bodies established before the Second World War. Only in 1965 the question of the scientific organization of businesses and after this year there have been many works of authors who have tackled specific areas of the management domain.

Human beings, said Aristotle is par excellence "politikon zoon", namely a social being, he always puts his questions about its existence in society, social groups to which it belongs. According to the Greek philosopher's conception, man cannot finish provided only within society to which he belongs. The first industrial revolution resulted in major changes to human working conditions, social and professional relations, social relations between classes for man it is not a "streamlined" a computing machine that operates on the cost efficient principal.

Modern management orientation toward what is termed the "social capital" based on the values, norms, conceptions, social rules of conduct to the companies also lead towards a "spiritualization" of economic life.

\section{Implicationof management in sociology}

A major influence exercised over management and sociology. With it managers can study the complex relationship management processes and the interplay between social and economic conditions of society. In this respect the manager can study and adopt the necessary measures for the establishment and behavior of groups. According to the statements of Anthony Giddens, sociology is the study of human social life, groups and societies.

Social actors claim that sociology studies social reality as a whole, but also concerns the parts, phenomena and processes of this reality, in their many and varied relationship to the whole. Sociology is a science that uses its own research methods to study the phenomena and processes of social reality. Sociologist goal is to achieve, by using scientific methods, objective and neutral approach in terms of axiological reality.

${ }^{5}$ Ibid, p. 82 
Sociology has been concerned since its inception by determination of the causes and conditions that determine or favor social movements and their mechanisms as they have generated a new approach to current management. The rule of the $4 \mathrm{C}$ (Coherence, Courage, Clarity and Consideration) guides effective management levers, while they are also found in sociological paradigms.

Consistency

- Consistency between words and deeds;

- Consistency between decisions;

- Consistency between objectives and funding

Courage - refers to the courage, intellectual and moral, of the manager, not the physical; having courage means taking decisions which are to assume, positively or negatively assess the activity of members, say what's right and what's wrong; psychological and moral courage (resistance to pressure)

Clarity: - Clear information for staff; practicing transparency; means:

- Clarifying the organization's mission, values to be respected, the criteria that will be appreciated subordinates;

- Accurate strategic choices and objectives;

- Regular communication of the results.

Consideration: - Paying attention, listening and respect of subordinates.

A performance management takes into account:

- "Rule of 4C"

- General factors: economic, sociological and political;

- Factors specific organization;

- Personal factors: style and personality of the manager.

Sociology ought to explain social realities as scientific facts and analysis derive from objective scientific truth by means of observation and measurement. Let's say that the evolution of sociological thought showed that, unlike research in the natural sciences interested in the study of causal relationships form because A causes B ,, and has the certain effect of C", human and social sciences analyze the probability that a c ,,case A influence on $\mathrm{B}$ and produce $\mathrm{C}$ and also effects $\mathrm{D}, \mathrm{E}$.... " . Therefore, these sciences are probabilistic. Social and human sciences studying people in their depiction of the individual and social beings, what the French sociologist P. Bourdieu led to say: "probably a curse that human sciences have to do with an object that speaks" $\underline{6}$

Management relationships are relationships established between members, between them and the components of other organizations in the fulfillment of management functions.

They can be collaboration or relationship conflict. Human relations management relations are formalized.

Depending on the nature of these relationships, the sphere of competence and the purposes, they can be divided into:

a) relations of authority, which can be:

- Relationships;

- Functional;

- Staff.

b) cooperative relations;

c) control relationships.

Authority relations are relations that are established between persons in the management process, when some have decision-making power over the other.

\footnotetext{
${ }^{6} \mathrm{http}: / /$ www.academia.edu//Sociologie_romaneasca modern
} 
- The relationship of hierarchical authority is that a leader $\mathrm{C}$ and only he decides on the contractor's, on the work that is a place for meeting organizational objectives.

- The relationship of authority functional specialization occurs due to work and occurs when a specialist $\mathrm{S}$ decides, directs and controls the activity of the specialty or E. S has authority over $\mathrm{E}$ only in terms of the method or methods they will use a smaller art. $\mathrm{C}$ remains the leader in all decision-making power on E. In practice these relationships usually occur between the heads of departments specializing in particular subjects or their ingredients and components operational divisions.

- The relationship of authority staff is the report established between a person or group of persons specialized (staff) who are delegated by senior management of the organization and departments heads or components involved in solving problems encountered, which led the delegation. A team staff has usually the most competent specialists in a field. The General Staff has no direct subordinates. The skilled staff is a participant in decisions to which the executive manager can be located on the same hierarchical level. However one or the other of the two may haveanother specialist on the other, depending on the contents of the relationship between them.

Between M1 executive manager and a specialist SM staff ratios may occur:

- M1 may decide without consulting the SM. SM's role is reduced to that of advisor, which uses voluntary M1.

- M1 can decide only after having consulted the SM.

- M1 cannot take a decision contrary to SM's proposal, in which case MS has upward decision on his M1.

The problem is solved unequivocally whether formalize concrete situations.

Cooperation ties designate the ratio of people on the same hierarchical level, but are part of different compartments. Such relationships arising from the necessity of carrying out complex activities involving several compartments. They consist of a correlation of shares exchanging information in order to achieve objectives.

Control relationships consist of the established specialized control bodies and persons contained in compartments organization. The relationship assumes the obligation to provide controlled by those who control all information requested but not as one who controls have decision-making power over the control.

The objectives of any organization carry out a set of work processes. In turn, work processes fall into two categories:

- Management processes, which are performed by managers;

- Execution processes performed by performers (subordinates).

The management process consists of phases that determines the overall objectives of the organization, the resources to achieve them and their contractors, which integrates and controls the work of staff using a complex of methods and techniques to achieve more efficient tasks.

Process management is exercised by managers, which is the system manager. Milestone management process is the management decision.

In the management process is delimitedfunctions (after $\mathrm{H}$. Fayol) provision, organization, command, coordination, control and evaluation.

Underlying all management functions and management decisions are information and communication. $^{7}$

\section{Management of media consumption}

\footnotetext{
${ }^{7}$ ttp://www.scritub.com/management/noțiuni General
} 
Public opinion is the product of people's mind reactions and the amount of individual thinking forms group thinking. In social space thinking there are many groups that interact and from this point of view there are many kinds of messages to reach one or the other groups. Interest groups and their desires overlap and influence each other inevitably. Progress results from continuous interaction of these groups and giving up some ideas for new ones. This happens after consumption. The area consumption is a field where goods and structured social needs and other cultural traits transiting from one group to the other categories social model as it transforms itself.

Consumption is based on information system which was dominant in the late twentieth century through a direct and continuous information. This has contributed to the transformation of political and social life as can be seen especially in the media because television gave a dominant position in the media system, press and radio obliging in relation to redefine it. Today is the whole social actors who had to learn the rules of media to promote their activity. Also changes lead to alterations in the interests and viewpoints of those whom they affect and change default group and individual reaction. This should be done with a mancentered management and aspirations.

\section{Conclusions}

All these transformations of management concepts were developed over time in the social space because it is a symbolic space, cultural, communicational but particularly important for business management.

Management then applies by analyzing the individual problem then analyzing public thinking. The reaction occurs using communication media between the individual and the mass of people bringing the two stakeholders to a common denominator and creating symbols that public thinking to answer.

\section{Bibliography}

1. Androniceanu, A., Change Management, All Educational Publishing, Bucharest, 1998 ;

2. Baudrillard, Jean, Consumer society. Myths and structures, Comunicare.ro, Bucharest, 2008;

3. Bondrea Aurelian, Sociology public and media, Publishing Foundation "Romania tomorrow", Bucharest, 1997;

4. Mihai Coman, From the backstage of the fourth powers, Publisher Carro, Bucharest, 1996;

5. Burduş, E., Management Treaty, Economic Publishing House, Bucharest, 2005;

6. Certo, S., Modern management, Teora Publishing House, Bucharest, 2002;

7. Ciobanu, I., Strategic Management, Polirom, Iaşi, 1998;

8. Drucker, PF, La practique de la direction des entreprises, Les Editions d`Organisation, Paris, 1957;

9. Guy Lochard, Henri Boyer, Media communication Uh, European Institute, Iasi, 1998;

10. The starling. Arguments "pro" AND "cons" of the country adopting the term "management" in Romanian language, Discussion Forum organized by the magazine, no. 2, 1971; 2000;

11. Mucchielli, Alex, Art of influencing. Analysis handling techniques, Polirom, Iaşi, 
12. Petrescu. I, Management, Publishing Holding Reporter, Bucharest, 1991;

13. Petrescu, I., ManagerialPsychosociologyPublishing Lux Libris, Braşov, 1998;

14. Petrescu, I., Cindrea, I. (eds.), Theory and practical in human resources management, Publisher Lux Libris, Braşov, 1998.

*** http://www.academia.edu//Sociologie_romaneasca modern

*** http://www.scritub.com/management/Noţiuni General

$* * * \mathrm{http}: / / \mathrm{www}$.academia.edu//Sociologie_romaneasca modern

***http://www.scritub.com/management/noţiuni General 